\title{
Abstracts of papers to be presented at the 12th annual meeting of the Psychonomic Society, November 11, 12, and 13, 1971 Chase-Park Plaza, St. Louis, Missouri
}

\section{ANIMAL LEARNING-I}

9:00-9:15 (13)

Autoshaping and Contextual Illumination: Selection of Behavior and Its Orientation Toward the Most Predictive Cue, EDWARD A. WASSERMAN, BARRY S. MARKMAN, \& ELIOT HEARST, Indiana University-When key illumination signaled free grain in a constantly lit chamber, pigeons pecked the lighted key. Identical pairings in a dark chamber brought forth characteristic idiosyncratic ("superstitious") behaviors, but not keypecking. These and other findings suggest that autoshaped pecking will occur only if key-localized cues predict food better than do diffuse (contextual) changes.

$$
\text { 9:15-9:30 (14) }
$$

Response Shaping: How Far and How Soon You Change Reinforcement Criterion Makes a Difference. DAVID A. ECKERMAN, University of North Carolina-Pigeons' keypecking falling within a particular 1-in. zone (unmarked) of a 10-in.-wide key was reinforced. This zone was moved by $N$ in. every $M$ reinforcements for several sweeps of the key. Shaping effectiveness (response stereotypy) was greater with small, infrequent changes in this zone.

$$
\text { 9:35-9:50 (15) }
$$

Schedule-Induced Escape from Fixed-Interval Reinforcement. THOMAS G. BROWN \& RANDALL K. FLORY, Hollins College (read by Randall $K$. Flory)-Pigeons keypecking on fixed-interval food schedules pecked a second key which produced escape periods consisting of a visual stimulus change and extinction. A second response on this key restored food schedule conditions. As fixed-interval value was increased logarithmically from 30 up to $960 \mathrm{sec}_{\text {, escape behavior }}$ increased to a maximum and then decreased.

$$
\text { 9:50-10:05 (16) }
$$

Positive and Negative Generalization Gradients of Stimulus Duration. IVAN BEALE, University of Auckland, WERNER K. HONIG, \& DENIS LANDER, Dalhousie University (read by W. K. Honig)-Pigeons controlled the duration of stimuli presented after discrimination training in a generalization test. Responses to an "advance key" produced the next stimulus in the test series. Both positive (decremental) and negative (incremental) gradients have been obtained with this procedure, and their form is similar to gradients based on response rate.

$$
\text { 10:25-10:45 (17) }
$$

Stimulus Generalization as a Function of Errorless Learning. WILLIAM D. KLIPEC \& JOSEPH LYONS, University of Arizona-Three groups (4 Ss per group) of pigeons learned a discrimination between a $555 \cdot \mathrm{nm}$ stimulus $(\mathrm{S}+)$ and a $538-\mathrm{nm}$ stimulus (S-). Group 1 was given errorless training via the fading procedure developed by Terrace (1963). However, the discrimination proved to be too difficult for these birds to learn errorlessly. Group 2 learned the discrimination errorlessly via the response prevention method developed by Lyons (1969). Group 3 also learned the discrimination errorlessly but with a procedure which combined the fading in of $\mathrm{S}$ (both duration and intensity) with the response prevention contingency. Groups 2 and 3 not only learned the discrimination errorlessly but also learned it faster and with fewer "errors" (i.e., attempts) than did the Ss in Group 1. A postdiscrimination generalization test revealed a much greater tendency for the birds in Group 1 to show a peak shift than for Ss in either of the other two groups.

$$
\text { 10:45-11:00 (18) }
$$

Stimulus Control in a Concurrent Discrimination. CHARLES R. LEITH \& DONALD A. RILEY, University of California, Berkeley-Blough (1969) reported attention-like behavior in 3 pigeons in a performance (not learning) task. We examined a possible learning artifact in Blough's paradigm by manipulating the reinforcement schedule in a task that was similar in design but radically different in most details. In spite of differences in design and control for reinforcement history, we got his effect in 2 pigeons.

$$
\text { 11:05-11:25 (19) }
$$

Abstract Concept Learning in Pigeons. THOMAS ZENTALL, University of Pittsburgh-Pigeons trained on a red-green, matching-to-sample or oddity-from-sample task learned a new yellow-blue matching or oddity task faster when that task involved the same concept as the first task than if the concept was changed. The results suggest that pigeons are capable of forming abstract concepts.

$$
11: 25-11: 35(20)
$$

Activation of Domestic Chicks as a Function of the Intensity of Stimulus Change. MERLE E. MEYER \& LOUIS G. LIPPMAN, Western Washington State College - Nineteen chicks were assigned randomly to each of 7 light-intensity conditions. Following light deprivation, each bird was exposed to 130 -min session during which 300 repeating cycles of $3-\mathrm{sec}$ light presentation alternated with darkness. Total responses were analyzed with respect to intensity, light onset-offset, and time intervals (in seconds) and yielded significant differences for all main effects and all interactions among these variables (ps $<.001$ ). Repeated intermittent light presentation yielded differential effects over the 7 intensities, with a curvilinear trend of activation which approximated the trend reported for sensory reinforcement of these organisms.

$$
\text { 11:40-11:55 (21) }
$$

Responding Under DRL Schedules of Reinforcement in the Crow. ROBERT W. POWELL, University of South Florida-Four crows were studied under DRL schedules ranging from 10 to $120 \mathrm{sec}$, with Prime dog food as the reinforcer. A standard pigeon test chamber was used. Their performance was far superior to that of pigeons in terms of number of responses per reinforcer and percentage of reinforcers obtained. DRL behavior in the crow is more rat-like than pigeon-like.

\section{PSYCHOPHARMACOLOGY}

$9: 15-9: 30(22)$

Effects of Parachlorophenylalanine on Behavior of Rats in the Runway. J. M. BLOOM \& J. M. PHILLIPS, Texas Research Institute-PCPA and control Ss were trained in the runway on an odor-discrimination task. The results showed that PCPA appears to increase sensitivity to odors but decreases reactivity. Long-term administration of PCPA did not affect drive or incentive motivation and had no adverse physiological effects.

$$
\text { 9:30-9:45 (23) }
$$

Methamphetamine Enhancement of Successive Discrimination Reversal Learning. WILLIAM H. CALHOUN \& BEVERLY M. KULIG, University of Tennessee-Rats 
were trained with an instrumental procedure to make successive discrimination reversals. Two groups were administered an injection of methamphetamine before Reversal 2. The drug groups were superior to a placebo group in terms of trials and errors to criterion over the remaining 6 successive reversals, hence demonstrating a facilitation of complex learning by this drug.

$$
\text { 9:50-10:10 (24) }
$$

Marihuana and the Rat's Preference for Earned in Comparison with Free Food. BROOKS CARDER, University of California, Los Angeles-Rats were trained to leverpress for food and then tested for leverpressing in the presence of free food. In Ss previously treated with the drug, marihuana decreased the rats' preference for earned food. In Ss naive to the drug, marihuana increased the preference for earned food.

$$
\text { 10:10-10:30 (25) }
$$

Behavioral, Biochemical, and Neuroanatomical Effects of Induced PKU. ROBERT L. SCHALOCK \& PAUL SIMMERING, Hastings College-A general review of the findings to date (2 years) regarding: (1) the operational definition and measurement of the intellectual and behavioral analogs in induced PKU rats, and (2) the determination of the relationships between cortical damage, measured learning ability, and behavioral change. Behaviors evaluated include DRL and classical avoidance learning, activity, exploration, sociability, fear, and aggression. Biochemical measures include serum phenylalanine levels and hydroxylase levels. Electronmicroscopic measures include 5 cortical and 1 subcortical area.

$$
\text { 10:50-11:05 (26) }
$$

Reversible and Irreversible Experimental Hyperglycemia in Conditioned Taste Aversion. CHARLES N. STEWART, KENNETH H. BROOKSHIRE, Franklin \& Marshall College, \& HEMMIGE N. BHAGAVAN, Research Institute, St. Joseph Hospital-Rats made diabetic and hence permanently hyperglycemic by means of alloxan or streptozotocin injection display an aversion to sodium saccharin, but not to sucrose or glucose, an aversion which persists as long as the animal remains diabetic. When rats are made temporarily hyperglycemic by injection with glucosamine, which inhibits glucose utilization, they develop an aversion to saccharin which is still evident when they are tested 7 days after they have returned to normal glycemic state.

\section{1:05-11:20 (27)}

Some Variables Altering Amphetamine-Activity Relationships. M. LEE DICKINSON \& WALTER ISAAC, University of Georgia (read by Walter Isaac)-The effect of d-amphetamine (placebo, .2, .4, .8 $\mathrm{mg} / \mathrm{kg}$ ) upon the activity of high-and low-activity groups of rats was studied in the light and dark. Amphetamine eliminated the activity-reducing effect of light. The high-activity group showed a smaller illumination difference than the low-activity group.

\section{1:25-11:40(28)}

Effects of Psychotropic Compounds on the Aggressive Behavior of Mice. EDWARD T. UYENO, Stanford Research Institute-The results of the dose-response experiments show that the inhibitory effects of trimethoxyamphetamines on the isolation-induced aggression of mice were dose-dependent. The finding that hallucinogenic 3-, 4-, 5-trimethoxyamphetamine (TMA) and 2-, 4-, 5-trimethoxy amphetamine (TMA-2) were significantly more potent than their nonhallucinogenic analog 2-, 3-, 4-trimethoxyamphetamine (TMA-3) is consistent with our previous data obtained from testing the squirrel monkey in the Wisconsin General Test Apparatus. 11:40-12:00 (29)

Factors Affecting Amphetamine Self-Administration in Squirrel Monkeys. ROGER STRETCH \& GARY J. GERBER, University of Saskatchewan-Following extinction of a drug-reinforced operant, pretreatment with the drug reinstates the overall pattern of self-administration behavior despite the fact that responding is no longer reinforced with IV infusions of the drug. Results are difficult to interpret if drug self-administration behavior is conceptualized solely as an operant reinforcement effect.

$$
\text { 12:05-12:20 (30) }
$$

Determination of Aversive Thresholds in the Rat Using Repeated Measures. VINCENT P. HOUSER, VA Hospital, Perry Point, Md.-The present paper presents a technique which objectively measures aversive thresholds in rats over repeated trials. Rats are placed in a rectangular tilt cage, one-half of which is electrified with various intensities of shock. The aversive threshold is defined as that intensity the animal avoids $75 \%$ of the time. This technique can detect analgesia in animals given various narcotic and nonnarcotic analgesics at doses lower than previously reported. Variability within Ss is low, allowing one to obtain extremely consistent dose-response curves.

\section{PUNISHMENT \& AVOIDANCE}

$$
\text { 9:15-9:30 (41) }
$$

Effects of Fixed-Interval Punishment During the Extinction of Sidman Avoidance in the Pigeon. KENNETH B. MELVIN \& PATRICK GRIFFIN, University of Alabama-Pigeons were trained to press a treadle on a Sidman avoidance schedule. During extinction, FI 5- or $10 \cdot \mathrm{min}$ punishment sustained responding relative to nonshock control conditions, although all birds eventually ceased to respond. Concurrent avoidance-FI punishment increased rates in training but led to rapid extinction.

$$
9: 30-9: 45(42)
$$

Discriminated Punishment and Collateral Behavior. JOHN B. CARMAN, University of North Dakota-Changes in lever press, lever touch, and locomotor activity were assessed with rats during discriminated punishment, "passive" extinction (lever removed, free food), and generalization testing. The magnitude of locomotor activity covaried with lever pressing and touching during punishment training and extinction. Activity generalization curves peaked after initial uniform depression. A transient residual effect of the punishment contingency remained for lever pressing and touching after passive extinction.

$$
\text { 9:50-10:05 (43) }
$$

Displacement of Shock-Induced Aggression. SYLVIA DULANEY, ROGER ULRICH, JAMES SCHERRER, \& RUSSEL JONES, Western Michigan University-A squirrel monkey restraining chair equipped with 2 rubber hoses measured biting attack in response to electric tailshock. Shock baseline involving response-independent fixed-time shock delivery gave records of biting attack on each hose. During punishment, only bites on the preferred target were followed by tailshock. Punishment for biting 1 hose caused abrupt increases in biting rate on the other. When Ss no longer bit the punished hose, nonpunished biting remained extremely variable between sessions and never returned to a base rate of biting. During a postpunishment shock, baseline biting behavior gradually returned to previous levels on both hoses.

$$
\text { 10:05-10:20 (44) }
$$

Avoidance Conditioning with Shock Contingent Upon the Avoidance Response. JOSEPH V. LAMBERT \& P. J. BERSH, Temple University-Rats learned a leverpress "avoidance" response which was met with 1 immediate shock but was instrumental in avoiding 5 identical shocks programmed to occur later. This response was learned both with and without correlated escape training. Results are interpreted in terms of a shock-frequency reduction approach to avoidance conditioning.

$$
\text { 10:40-10:55 (45) }
$$

Attenuation of the Kamin Effect by Cholinergic-Adrenergic Manipulations. ROBERT J. 
BARRETT \& OAKLEY S. RAY, V.A. Hospital \& Vanderbilt University-Previous studies have indicated that the Kamin effect is due to shock-induced response suppression rather than to changes in memory processes. The present experiment, using CDF male rats in a $Y$-maze active-avoidance task, supports this view in that pharmacological manipulations which effectively reduced response suppression also attenuated the Kamin effect.

$$
\text { 10:55-11:10 (46) }
$$

The Relative Aversiveness of Signaled vs Unsignaled Escapable and Inescapable Shock: An Analysis of Choice. STUART CULBERTSON, The American University, \& PIETRO BADIA, Bowling Green State University-A free-operant procedure was used to study choice for signaled over unsignaled shock under escapable (Experiment 1) and inescapable (Experiment 2) conditions. All Ss in both studies chose signaled over unsignaled conditions. The findings indicated that stimuli identifying the shock-free period controlled choice behavior and that the signal identifying the shock period did not.

$$
\text { 11:15-11:25 (47) }
$$

Conditioned Gustatory Aversion Produced with Anesthetic and Convulsive Agents. DAVID LOUIS BROWN \& MURRAY GLUSMAN, New York State Psychiatric Institute-Rats avoided saccharin after 1 learning trial when saccharin drinking was followed by intravenous injection of sodium pentobarbital, chloral hydrate, or pentylenetetrazol. Ether produced much less aversion unless administered repeatedly. These results have implications concerning the sufficient conditions for acquired taste aversion and suggest a set of safe, familiar punishing agents.

$$
11: 25-11: 45(48)
$$

Incentive Shifts for Aversively Motivated Behavior. R. CHRIS MARTIN, University of Missouri at Kansas City, \& JAMES $H$. NEELY, Yale University-Changes in type of avoidance (1-way or 2-way) were manipulated in a 2 by 2 factorial design. The results were analogous with those obtained in appetitively motivated situations involving changes in magnitude of reinforcement. Advantages of this method of studying incentive shifts in aversively motivated situations are discussed.

$$
\text { 11:50-12:05 (49) }
$$

Flooding (Response Prevention) in Rats: The Effects of Immediate vs Delayed Flooding. MORRIE BAUM, Bishop's University-An experiment was conducted to determine a new method for increasing the effectiveness of flooding (response prevention) in producing rapid avoidance extinction. The study showed that flooding was more effective if a cooling-off or delay period was allowed to pass following acquisition and prior to the administration of flooding.

$$
\text { 12:05-12:20(50) }
$$

Reinstatement of the U-Shaped Retention Function Following Avoidance Training. J. MICHAEL BOWERS, University of Oregon Medical School, \& F. ROBERT BRUSH, Syracuse University (read by F. Robert Brush)-Performance during retraining of a shuttlebox avoidance response by rats is a $U$-shaped function of time after original training. Free shock, given in another apparatus $23 \mathrm{~h}$ after original training, when performance has normally recovered, is sufficient to initiate another $U$-shaped function with a time course, measured from the time of free shock, that is similar to that following original training.

\section{ANIMAL LEARNING-II

$$
\text { 1:00-1:20 (70) }
$$

Teaching Sign Language to a Chimpanzee. V: A Practical Vocabulary Test for Young primates. R. ALLEN GARDNER \& BEATRICE T. GARDNER, University of Nevada-Development of a double-blind vocabulary test for
Washoe's repertoire of signs; its use to demonstrate the generality of referent classes and the conceptual relationships between signs; and its use to measure the intelligibility of Washoe's signing when deaf strangers serve as Os.

$$
1: 20-1: 40(71)
$$

Teaching Sign Language to a Chimpanzee. VI: Replies to Wh Questions. BEATRICE T. GARDNER \& R. ALLEN GARDNER, University of Nevada-A systematic sampling of replies to questions containing Who, Whose, What, and Where showed that the chimpanzee, Washoe, produced different types of replies to different interrogative signs, i.e., signs for persons to Who questions, signs for objects to What questions, etc. Comparable findings on the use of vocal language by young children will be discussed.

$$
1: 45-1: 55(72)
$$

Sequential Factors in $\mathrm{S}-$ Discrimination Contrast. PHILIP A. MEYER, University of South Dakota-At 2 trials per day, 4 groups of rats $(N=12)$ received 40 days of training in a black-white parallel runway. Three groups were differentially conditioned with large (L) and small (S) reward magnitudes. These groups differed with respect to the use of an L-S and/or S-L transition within days. Relative to an $\mathrm{S}-$ control group, $\mathrm{S}-$ performance was depressed only when L-S transitions had been experienced. 1:55-2:05 (73)

Electroconvulsive Shock Effects on Conditioned Heart Rate and Suppression of Drinking. W. F. CAUL \& R. J. BARRETT, Vanderbilt University-Electroconvulsive shock (ECS) given rats at 1 or $10 \mathrm{sec}$ after footshock attenuated the bradycardic response to a stimulus which developed over trials in rats not given ECS. Suppression of licking was also affected by ECS which, together with the heart-rate data, indicates a high degree of correspondence between the manipulation ofheart and behavioral responses by ECS treatment.

$$
2: 10-2: 20(74)
$$

Does the Frustration Effect Dissipate as Discrimination Develops? RICHARD L. PATTEN, REGINALD L. HENDRICKS, \& ANTHONY E. BIBLE, Iowa State University-The double-runway was employed to determine if the frustrative reaction to nonreward or reduced reward declined as Ss discriminated between first-alley cues associated with large and small or zero reward. The results of within-s and between-S comparisons indicated exceptions to current theory relating frustration to discrimination.

$$
2: 20-2: 30(75)
$$

Infantile Handling and Resistance to Extinction With or Without Shock Following Food-Reinforced Runway Acquisition. HELEN B. DALY \& KENNETH M. ROSENBERG, SUNY at Oswego-Rat pups which were either "handled" or not "handled" for the first 20 days after birth were given runway acquisition to food in adulthood, followed by extinction training with or without shock. Early handling increased resistance to shock, but had little effect on extinction without shock.

$$
\text { 2:50-3:05 (76) }
$$

Reacquisition as a Function of Acquisition Reward Schedule. WILLIAM P. DUNLAP \& LAWRENCE DACHOWSKI, Tulane University (read by Lawrence Dachowski)-Forty-eight rats received 72 acquisition trials in a runway for $0 \%, 50 \%$, or $100 \%$ reward. Following extinction, all Ss received 40 rewarded trials. Reacquisition running speeds were greater for $50 \%$ Ss than for $100 \%$ Ss after 72 extinction trials, but not after 144 extinction trials, while $0 \%$ Ss were always slowest. 3:05-3:20 (77)

Long-Term Retention in the Rat. OAKLEY S. RAY \& ROBERT J. BARRETT, V.A. Hospital \& Vanderbilt University-Sixty-day-old male F344 rats received 0,20 , 40 , or 80 brightness discrimination trials in an automated 
aversive $Y$-maze. After 1, 30, 90, 180, and 270 days, independent groups received 150 trials (0-trial Ss held in the lab for the interval were trained and tested 1 day later). Final performance was related to original trials, interval, and age.

$$
\text { 3:25-3:40 (78) }
$$

Pavlovian Higher-Order Conditioning of the Excitation and Inhibition of Fear. R. G. WEISMAN, J. S. LITNER, \& M. DI FRANCO, Queen's University-The establishment of Pavlovian inhibition of fear through contrast with shock is, now, an accepted procedure. The present experiments show that second-order conditioning of excitation and inhibition occur when first-order Pavlovian stimuli are contrasted with originally neutral stimuli. Second-order conditioning through pairing was also observed.

$$
\text { 3:40-3:45 (79) }
$$

(Read by title only)

Spatial Reversal Learning in Rats and Gerbils. MAUREEN A. CAREY \& GLORIA J. FISCHER, Washington State University-Hooded rats and gerbils were trained to criterion on a spatial discrimination in a T-maze, followed by 15 daily 10 -trial reversals. Both species were run 22 h.d. food for 3 (rats) or 1 Noyes pellet (gerbils). These were comparable proportions of their average ad lib intake. Results were that both species improved over successive reversals, with rats making slightly, but reliably, fewer errors per reversal than gerbils. Gerbils also were observed to explore more, which may have interfered with their accuracy. Whatever the reason, present and prior findings suggest that gerbils are slightly inferior to albinus on appetitive learning tasks.

$$
\text { 3:45-3:50 (80) }
$$

(Read by title only)

Resistance to Extinction as a Function of Partial Reinforcement and External Stimuli: A Within-S Design. A. GRANT YOUNG \& C. A. COSTELLOE, Louisiana State University, Baton Rouge-Ninety-six male albino rats were conditioned to leverpress for sucrose. The basic design of within-S groups was a 2 by 2 by 2 factorial incorporating light $O N$ or light OFF extinction conditions; training conditions which associated partial reinforcement with light $O N$ and continuous reinforcement with light OFF, or partial reinforcement with light $O F F$ and continuous reinforcement with light $O N$; and 1,600 or 3,200 total training trials. In addition, there was a $100 \%$ reinforcement condition constituting a 2 by 2 factorial of between-S groups incorporating light ON or light OFF extinction conditions and 1,600 or 3,200 total trials. Results showed that for within-S groups there were no differences in resistance to extinction, which suggests that the PRE cannot be attached to external stimuli. Results further showed no differences in resistance to extinction for between-S groups, either as a function of lighting or as a function of total training trials.

\section{PHYSIOLOGICAL}

Temporary Amnesia Produced by Pretraining Hippocampal Potassium Chloride: A Strength of Conditioning Effect. ALLEN M. SCHNEIDER, New York University, BRUCE S. KAPP, University of Vermont, \& STEVEN ROSENBERG, New York University-When hippocampal-KCl injections occurred 3 days before 1-trial conditioned-suppression training, rats tested 1 day later showed amnesia, but those tested 18 days later did not. Other rats injected before 4 training trials showed no amnesia. Implications for using hippocampal disruption in studying memory storage and retrieval are discussed.

$$
\text { 1:45-2:00 (82) }
$$

A Comparison of the Motivational Concomitants of Water-Deprivation and Carbachol-Induced Drinking in Rats. RICHARD A. HUGHES II, Virginia Polytechnic Institute \&
State University-Water-deprived rats drank more water than either $.9 \%$ or $1.8 \%$ saline, as did carbachol-injected rats that were not water deprived. Both groups drank more $.9 \%$ saline when neither water deprived nor drug injected. The motivational concomitant of the drug-induced drinking is like that induced by water deprivation.

$$
\text { 2:05-2:20 (83) }
$$

Avoidable and Unavoidable Shock and Gastric Secretion. WILlIAM P. PARE, VA Hospital, Perry Point, Md.-Chronic gastric fistula rats exposed to unavoidable shock demonstrate an inhibition of gastric secretion and an increase in total acid $(\mathrm{mEq} / \mathrm{l})$. Subsequent testing minus shock elicits the same gastric response. Gastric secretion is depressed during Sidman avoidance responding for low avoiders. High avoiders maintain an elevated total acid output for both avoidance and rest periods.

$$
\text { 2:20-2:30 (84) }
$$

Effect of Portal Infusions of Glucose on Licking Rates in the Rat. CONSTANCE S. CAMPBELL, University of mlinois Medical Center, \& JOHN D. DAVIS, University of Illinois, Chicago Circle-A single infusion of isotonic glucose into the portal vein of rats resulted in a depression in licking rates. The depression was maximal immediately after infusion, with a trend toward recovery after $10 \mathrm{~min}$ Duodenal infusions produced a similar pattern. Liver glucoreceptors could play a role in regulating food intake 2:35-2:45 (85)

Brain RNA Metabolism as a Function of Water Drinking. PAUL D. KOTTLER \& ROBERT BOWMAN, University of Wisconsin-Thirsty rats that have been in the laboratory for only 2 days show increased hippocampal RNA metabolism following ingestion of water. Identical animals that have been adapted to the laboratory environment for 1 week show, at most, marginal RNA changes following drinking. Several experiments investigating this phenomenon are presented.

\section{2:45-2:55 (86)}

Sodium Chloride Preference in Pinealectomized Rats. PATRICIA L. BATES, DAVID $K$. BLISS, \& PETER J. DONOVICK, SUNY at Binghamton-NaCl vs water preference was measured in pinealectomized and sham-operated rats. Lighting conditions and food sodium content were varied. Under constant lighting and normal diet, both groups were similar. Under diurnal lighting and a sodium-free diet, the $\mathrm{NaCl}$ intake of the pinealectomized animals was depressed relative to controls.

$$
\text { 3:15-3:30 (87) }
$$

Taste Aversions and Two Inhibitors of Protein Synthesis. HARDY C. WILCOXON, George Peabody College, JOHN T. WILSON, Vanderbilt University, \& $R$. STEPHEN FULMER, George Peabody College-Rats, given an IP injection $(0.2 \mathrm{mg} / \mathrm{kg})$ of actinomycin $D$ either $30 \mathrm{~min}$ before or $30 \mathrm{~min}$ after drinking sour water, showed aversions to the flavored water when it was next offered to them 3 days later. The "before" group showed stronger aversions than the "after" group. Similarly timed injections of actinomycin $D$ at $0.05 \mathrm{mg} / \mathrm{kg}$ and of puromycin at $20 \mathrm{mg} / \mathrm{kg}$ and $5 \mathrm{mg} / \mathrm{kg}$ had little or no effect.

$$
\text { 3:30-3:45 (88) }
$$

Effect of an RNA-Rich Extract on Acquisition of a One-Way Avoidance Response in Rats. DAVID H. MALIN, University of Michigan, ARNOLD M. GOLUB, Eunice Kennedy Shriver Center, \& JAMES V. McCONNELL, University of Michigan-Donor rats were trained to make a one-way avoidance response to avoid electric shock. Rats in control groups either received no training or were given yoked shock, but were prevented from learning the avoidance response. RNA extracted from the brains of these donors was injected intracranially into recipient rats which were then themselves trained. Recipients injected with "trained" RNA acquired the response more rapidly than did control-injected recipients. 
$3: 50-4: 00(89)$

Low-Protein Diet and Preference for a Sucrose and a Saccharin Solution. ELLEN R. BAUER, College of William \& Mary-Female rats were fed either $3.5 \%$ protein $(N=6)$ or isocaloric $26 \%$ protein $(\mathrm{N}=6)$ diet for 12 days. Four-day 2 -bottle preference tests were given using water, $0.5 \%$ sodium saccharin, and supposedly isohedonic $3.5 \%$ sucrose. Saccharin and sucrose were always preferred to water. Low protein did not affect saccharin consumption but drastically reduced sucrose consumption.

$$
\text { 4:00-4:10(90) }
$$

Food and Water Requirements of Woodrats as Indicated by Dietary Self-Selections. ARTHUR E. HARRIMAN, Oklahoma State University-Dietary requirements of Southern Plains woodrats (Neotoma micropus) were studied by Richter's self-selection of diet method. A mash composed of purified items from the self-selection array maintained both successful self-selectors and naive woodrats. Both groups fared as well as woodrats fed a commercial laboratory chow.

\section{REINFORCEMENT}

$$
\text { 1:15-1:35 (91) }
$$

A Comparison of the Conditional Reinforcing Effectiveness of Discriminative Stimuli with Brief Exteroceptive Stimulus Changes in Second-Order Schedules. DENNIS JOWAISAS, JO DeWEESE, \& E. F. MALAGODI, University of Florida-Pigeons responded on second-order schedules of the form FR 2 (FI 2) in which the completion of 2 successive FI 2 components produced primary reinforcement. Five types of FR 2 (FI 2) sequences were studied: standard chained schedules, chained schedules with added food-paired brief stimuli, chained schedules with added nonpaired brief stimuli, tandem schedules, and standard brief-stimulus schedules with both food-paired and nonpaired stimuli. The results indicate that the food-paired brief stimuli are more effective conditioned reinforcers than are discriminative stimuli when presented on identical schedules.

$$
1: 35-1: 50(92)
$$

Response Differentiation During Variable-Interval Reinforcement. DONALD E. MINTZ, RICHARD M. SAMUELS, \& NED G. BARBER, City College of CUNY-Rats were reinforced on a VI 1-min schedule with varied criteria for reinforcement based on the peak force of response. Force distributions showed general conformity to the force requirements. Overall response rate did not vary systematically with the force required, but a given criterion tended to produce a high rate of that subclass of response. 1:55-2:10 (93)

Effects of Interpolating Goalbox Placements or Runway Trials During Single Alternation Training. JOSEPH J. FRANCHINA, DONNA L. EAST, \& OKEY R. EVANS, Virginia Polytechnic Institute \& State University-Relative to controls without interpolation experience, interpolated runway trials or goalbox placements with alternating reward and nonreward equally facilitated alternation learning; interpolated placements or runs with $100 \%$ reward or nonreward equally impaired alternation learning. Randomly rewarded placements facilitated alternation learning, but less so than alternation placements; random runs were most impairing.

$$
2: 10-2: 25 \text { (94) }
$$

The Effect of $\mathrm{N}$-Length Order on Resistance to Extinction. DENNIS C. COGAN \& ROBERT BREAUX, Texas Tech University-Three groups of 10 male albino rats on 23-h food deprivation were run 12 trials per day in a straight alley under $50 \%$ reinforcement, using 1 of 3 different orders of occurrence of 1,2 , and 3 consecutive nonreinforced trials: increasing $\mathrm{N}$-lengths, decreasing $\mathrm{N}$-lengths, and random N-lengths. Results indicated increased resistance to extinction for the increasing $\mathrm{N}$-length group.
$2: 30 \cdot 2: 45(95)$

Within-Subject Partial Reinforcement Effects and Sequential Theory. ROGER L. MELLGREN, DENNIS G. DYCK, \& JEFFREY A. SEYBERT, University of Oklahoma-Rats were given partial reinforcement in one alley and continuous reinforcement in another alley, and then extinguished in both alleys. In acquisition, the occurrence of $N-R$ transition was varied such that $S^{N}$ would be conditioned to the partial continuous or both alleys. Extinction performance was determined by the locus of $\mathrm{N}-\mathrm{R}$ transitions.

$$
\text { 2:45-3:00 (96) }
$$

"Autoshaping" in the Rat Using Food and Brainshock USs. GAIL PETERSON, JAMES ACKIL, GABRIEL FROMMER, \& ELIOT HEARST, Indiana University-Presentation and illumination of a retractable lever signaled food delivery; another lever was presented randomly. Rats approached and frequently licked or bit the predictive lever, but ceased approaching the "random" lever. Rats given rewarding brainshock instead of food also specifically approached and contacted the predictive lever, but rarely licked or bit it.

$$
\text { 3:20-3:35 (97) }
$$

Selective Observing During Auditory Discrimination Learning. MICHAEL P. BROWNE, EDWARD A. WASSERMAN, \& JAMES A. DINSMOOR, Indiana University-By depressing a pedal, pigeons turned on a tone or a click-train which indicated whether intermittent reinforcement or extinction of keypecking was in effect. Otherwise, white noise sounded. Initially, birds sampled S+ and $S-$ equally and pecked indiscriminately. As the keypeck discrimination emerged, Ss exposed $\mathrm{S}-$ much more briefly than $\mathrm{S}+$.

\subsection{5-3:55 (98)}

The Effects of Various Signals for Free Food Upon Food Reinforced Behavior. ANTHONY L. RILEY, JOHN C. McMILLAN, \& VINCENT $M$. LoLORDO, University of North Carolina, Chapel Hill (read by Vincent $M$ LoLordo -Pigeons whose pecking was maintained by food on a DRL LH schedule received presentations of a tone followed by free food. The tone failed to facilitate keypecking. When the tone, accompanied by a stimulus change on the key, preceded free food but the visual stimulus alone was CS-, the compound produced marked facilitation, while CS- produced suppression.

$$
\text { 4:00-4:15 (99) }
$$

Contextual Effects on Excitatory and Inhibitory Gradients. JOHN W. DONAHOE, University of Massachusetts, \& AUGUSTUS $R$. LUMIA, Skidmore College-The purpose of the experiment was to determine the effects of generalization test procedures on excitatory, inhibitory, and postdiscrimination gradients of stimulus control. The presence of $\mathrm{S}+$ in the test series lowered the inhibitory gradient, while the presence of $\mathrm{S}$ - raised the excitatory gradient. The results of single-stimulus and resistance-to-reinforcement tests are also presented.

$4: 15-4: 20$ (100)

(Read by title only)

Differential Reinforcement of Specific Lick Rates in the Rat. STEPHEN C. PIERSON, Florida State University, \& ROBERT W. SCHAEFFER, Auburn University (Robert W. Schaeffer to answer questions)-Lick rates in rats were differentially reinforced using an operant conditioning procedure in which specific lick rates, when maintained for specific temporal durations, were reinforced with the opportunity to run in an activity wheel. Between and within Ss, lick rate variability did not exceed 1 lick for all conditions tested in which the time base was 1 sec or less. Specific momentary lick rates were successfully reinforced for all Ss tested, but conditioning did not produce momentary lick rates faster than those normally observed in baseline conditions. Administration of dl-amphetamine, a drug thought to have a facilitational effect upon speed of 
neurosynaptic transmission, had no effect on lick rate.

\section{ANIMAL CONDITIONING}

$$
\text { 1:30-1:45 (101) }
$$

Stimulus Selection in Compound Conditioning as a Function of $\mathrm{CS}_{1}-\mathrm{CS}_{2}$ Interval. DELOS D. WICKENS, ANTHONY F. NIELD, DAVID S. TUBER, \& CAROL D. WICKENS, Ohio State University-Three groups of cats were classically conditioned to a compound stimulus of light and tone, each at a different $\mathrm{CS}_{1}-\mathrm{CS}_{2}$ interval-150, 500, and 2,000 msec. Paw response to shock UCS was the CR. Tests were to the short or the long CS. Responsiveness to each element was a quadratic function of $\mathrm{CS}_{1}-\mathrm{CS}_{2}$ interval. Redundancy theory alone cannot handle the data. 1:45-2:05 (102)

Stimulus Generalization and Multiple-Unit Activity of Primary and Polysensory Cortical Areas of the Rabbit. MICHAEL GABRIEL \& RICHARD F. THOMPSON, University of California, Irvine-Multiple-unit neuronal activity was recorded from primary auditory cortex, from 3 association response areas of albino rabbit cortex during single-session avoidance conditioning, and during a test for stimulus generalization. The generalization test was run 24 or $48 \mathrm{~h}$ following acquisition, using an extinction procedure. Typical behavioral gradient-flattening following a 48 h delay, compared to $24 \mathrm{~h}$, was expected to occur for multiple-unit activity in association response areas but not in the primary auditory area.

$$
\text { 2:10-2:30 (103) }
$$

Effects of ISI Shifts on Rabbit Nictitating Membrane Conditioning. I. GORMEZANO \& S. R. COLEMAN, University of Iowa-The study employed acquisition ISIs of 200 and 700 msec and 3 subsequent ISI shift conditions (fixed, gradual, and abrupt) with 2 directions of ISI shift (short-to-long and long-to-short). From analysis of percentage, onset latency, peak latency, and topography of CRs, it was concluded that the instrumental response shaping hypothesis could not account for critical portions of the data.

$$
\text { 2:30-2:50 (104) }
$$

Conditioning the Glycemic Effect of Insulin in Rats. SHEPARD SIEGEL, McMaster University-Following a series of insulin injections (and resulting hypoglycemia), injection of a placebo led to an elevation in blood glucose. This apparent conditioned hyperglycemia contrasts with previous reports of conditioned, insulin-like hypoglycemia following training with the hormone. Four experiments assessed the parametric details of the phenomenon, the role of peeudoconditioning, and the replicability of the previously reported results.

$$
\text { 3:10-3:25 (105) }
$$

The Amygdaloid Area and Defensive Reactions in the Rat. ROBERT J. BLANCHARD, University of Hawaii-Rats with amygdaloid damage showed striking deficits in both freezing and active avoidance of conditioned shock stimuli. This pattern of deficits was repeated when a cat was used as the eliciting stimulus, suggesting a primary role of the amygdaloid area in the mediation of innate defensive reactions.

$$
\text { 3:25-3:35 (106) }
$$

Habituation to Illness: Effects on Acquisition and Retention of a Conditioned Taste Aversion. KENNETH $H$. BROOKSHIRE, Franklin \& Marshall College, \& ROBERT M. BRACKBILL, University of Minnesota-Ten days of prior exposure to apomorphine hydrochloride prevented this illness-producing agent from serving as the US in subsequent taste aversion learning, but retention of a taste aversion was unaffected by interim apomorphine injection, even though in both cases drug tolerance was not observed. 3:40-3:55 (107)

Pavlovian Aversive Conditioning and Its Interaction with Appetitive Discrimination Learning. HARRY FOWLER,
University of Pittsburgh, GEORGE C. FAGO, Ursinus College, \& EDWARD DOMBER, Drew University-A conditioned fear excitor (CS+) for the correct food-reinforced response can facilitate discrimination performance in contrast to CER suppression, whereas a conditioned fear inhibitor (CS-) can retard performance even when its reinforcing action (fear reduction) is potentiated by punishment for the incorrect response. The findings highlight a general "signaling" property of CS events.

$$
\text { 3:55-4:05 (108) }
$$

Classical Conditioning in Leeches. TOM HENDERSON \& PASCHAL N. STRONG, University of South Florida (read by $P$. N. Strong-Leeches were classically conditioned using 2 UCS (shock) intensities, 2 CS (light) intensities, and paired vs unpaired CS-UCS combinations in a 2 by 2 by 2 factorial design. Clear-cut conditioning was obtained with a significant UCS intensity effect and spontaneous recovery during the second day of extinction.

$$
\text { 4:10-4:25 (109) }
$$

Current Research in Pavlovian Conditioning. PETER W. FREY, Northwestern University-Informal talk on some current research of interest to the author on investigations in rabbit eyelid conditioning or gerbil fear conditioning. Possible topics include (1) brain stimulation effects in Pavlovian conditioning, (2) signal detection analysis of differential conditioning experiments, (3) math model simulation of differential conditioning, and (4) a comparison of Pavlovian and Thorndikian reinforcement principles in rabbit eyelid conditioning.

\section{ANIMAL BEHAVIOR}

9:00-9:15 (154)

Cooperative Problem Solving by Rat Triads. MILTON E. ROSENBAUM, STEPHEN W. EPLEY, \& ETHERA D. BROWN, University of Iowa-Rat triads were exposed to a mixed-motive problem requiring the interdependent behavior of at least 2 rats to obtain food necessary for survival. Three rats responded successfully to the situation, although the mode of solution differed considerably among triads. Transfer to a new situation requiring similar interdependency was accomplished readily.

$$
\text { 9:15-9:25 (155) }
$$

Differential Schedule Performance as a Function of Mlumination and Strain. AL L. CONE, PARKER TEEL, \& DALLAS JOHNSON, Lynchburg College-Effects of illumination level on FI, FR, and mult FI FR response rates were investigated using hooded and albino rats. Illumination produced differential response rates which were dependent upon strain, schedule, and whether Ss were single schedule or mult.

$$
\text { 9:30-9:40 (156) }
$$

Lick Rates in Opossum. DONNA M. CONE, ANTHONY J. GOLDEN, \& SIDNEY L. SANDERS, Lynchburg College-Licking for water was measured in 412 -h deprived opossum. Mean rate was 3.36 licks/sec, with a standard deviation of 0.35 and a range of 1.8-6.0. Both sexes licked faster at 10 p.m. than at 10 a.m., and the males displayed more variability in lick rate at night.

$$
\text { 9:40-9:50 (157) }
$$

Changes in Dominance in Guinea Pigs. FRANK $\mathbf{N}$ WILLIS, University of Missouri, Kansas City, \& ARVIN OKE, University of Kansas (read by Arvin Oke)-Observations of a colony of guinea pigs revealed a clear dominance hierarchy among the males. Unlike the hierarchies in most species, however, dramatic changes occurred periodically. It was found that the changes invariably followed 1 of 2 events, the introduction of a new male into the colony or the postpartum estrus of any female in the colony.

$$
\text { 9:55-10:10(158) }
$$

Endocrine Effects of Grouping and Dominance Rank in 
Squirel Monkeys. ALAN I. LESHNER \& DOUGLAS K CANDLAND, Bucknell University-Squirrel monkeys colonized for 4 years showed higher urinary 17-hydroxy-corticosteroids than isolated animals. Among the colonized group, dominant animals showed higher corticosteroid and lower catecholamine levels. Rodents show a different pattern. We interpret this as reflecting the different ways in which rodents and primates form societies.

\section{0:10-10:25 (159)}

The Effect of Distribution of Trials Upon Tonic Immobility in the Tarantula, Aphonopelma californica. F. T. CRAWFORD, Florida State University-Three groups of 4 tarantulas each were tested for duration of tonic immobility. The groups were given: (1) 12 trials a day for 2 days, (2) 4 trials a day for 6 days, or (3) 1 trial a day for 24 days. The results indicated that the mean duration of the tonic immobility state was maintained best by Condition 1 and least well by Condition 3

\section{0:45-11:00 (160)}

Tonic Immobility in the Chick as a Function of Age and Experience. A. M. PRESTRUDE \& L. R. CRAWFORD, Virginia Polytechnic Institute \& State University-This study investigated the relative effects of age and number of daily immobility trials on the rate of habituation of the immobility response in chicks. Five age groups received 3 and 10 immobility trials per day until they were 21 days of age. All groups responded maximally at Day 5. All 10-trial groups habituated faster than their 3-trial counterparts. Implications for the fear hypothesis are discussed.

$$
\text { 11:00-11:15 (161) }
$$

The Effect of Different Dimensions of Social Stimulation on Tonic Immobility in Chickens. GORDON G. GALLUP, JR., \& ERIC T. SWANSON, Tulane University-The presence of a live conspecific in the testing situation was found to reduce the duration of immobility in young group-reared chicks. On the other hand, birds which were manually restrained in front of a mirror showed exaggerated immobility reactions. By manipulating the characteristics of dead conspecifics, an attempt was made to determine why a mirror prolongs the immobility episode

\section{1:20-11:35 (162)}

Effect of Cage Size on Imprinting and Open-Field Behavior of Chicks. ROBERT T. BROWN \& FAYE B. STEUER, University of North Carolina-Chicks were raised individually in small or large cages, each of which was empty (Experiment 1) or contained an imprinting object (Experiment 2). In Experiment 1, small-cage chicks showed higher emotionality than did large-cage chicks in an open field. In Experiment 2, small-cage chicks had longer approach latencies to the imprinting object in the open field.

$$
11: 35-11: 50(163)
$$

Hormone and Brain Control of Territoriality in the Gerbil. DELBERT THIESSEN, University of Texas at Austin-Castrate Mongolian gerbils can be induced to scent-mark territories when testosterone is implanted into the preoptic area of the hypothalamus. Other brain areas are unresponsive. Actinomycin $\mathrm{D}$, puromycin, and to some extent ribonuclease inhibit the hormone response. The hormone may act by inducing localized gene action.

$$
11: 55-12: 10(164)
$$

Is Learning Unnatural? ROBERT BOICE, University of Missouri, Columbia-There is little evidence that learning behavior is common or important in adult wild animals. Psychology's emphasis on learning is seen as the distorted product of bored domesticated animals selected for learning ability, the playful dissociation of appetitive and consummatory behaviors in domesticated man, and laboratories which artifactualize natural processes such as perceptual sharpening into more complicated learning phenomena

\section{BRAIN STIMULATION}

$$
8: 45-9: 00(165)
$$

Inhibition of Chemically Elicited Feeding and Drinking by Autonomic Blocking Agents. DANIEL J. LONOWSKI \& ROBERT A. LEVITT, Southern Illinois University (read by Robert $A$. Levitt)-Feeding and drinking can be elicited by the intracerebral injection of norepinephrine and carbachol, respectively. The effects on these responses of intracerebral injection of the adrenergic and cholinergic antagonists, phentolamine and regitine, were investigated. The antagonists were injected into either the same site as the stimulants or into other sites Selective inhibitory effects were obtained.

\section{9:00-9:15 (166)}

Electrical Self-Stimulation and Inhibition of Feeding in the Ventromedial Hypothalamus. GORDON G. BALL, Rockefeller University-Contrary to earlier reports, animals learned to barpress for electrical stimulation of the ventromedial hypothalamus. When hungry, they also stopped feeding during stimulation. There was a positive correlation between the current required to elicit self-stimulation and that required to stop feeding.

$$
\text { 9:20-9:40 (167) }
$$

Efficient Deconditioning of Avoidance. LARRY D. REID, CONSTANCE L. TAYLOR, \& LINDA M. RASSEL, Bradley University-Rats with hypothalamic electrodes pressed a lever to avoid signaled footshock. Before testing for persistence of pressing after footshock discontinuance, different presentations of the signal with and without pairing of hypothalamic stimulation were imposed. Intense positive brain stimulation, paired with the signal used in initial training, led to rapid reduction of pressing.

$$
\text { 9:40-9:55 (168) }
$$

The Role of the Posterior Hypothalamus in Behavioral Thermoregulation. ELEANOR R. ADAIR, John B. Pierce Foundation \& Yale University-Local thermal stimulation of the posterior hypothalamic area can motivate thermoregulatory behavior nearly as effectively as comparable stimulation of the medial preoptic/anterior hypothalamic area. However, unlike the preoptic area, the posterior hypothalamus appears to exert no control over physiological mechanisms of heat production and heat loss. 10:15-10:30 (169)

Inhibitory Patterns in Rat Hippocampus. S. T. KITAI, T. SHIMONO, \& J. DeFRANCE, Wayne State University-Patterns of inhibition between antidromically and orthodromically activated pyramidal cells in the CA1 and CA2 areas of rat hippocampus were studied by microelectrode technique. Differences in inhibitory patterns will be discussed from a point of view of differences in effective sites of inhibitory interneurons on pyramidal cells

$$
\text { 10:30-10:45 (170) }
$$

Inhibition in the Septum. J. F. DeFRANCE, T, SHIMONO, \& S. T. KITAI, Wayne State University-Single shocks to hippocampal-septal pathways produce monosynaptic EPSPs and polysynaptic IPSPs in the lateral septal nucleus. Interaction between the fornix and fimbria systems shows long-lasting response inhibition. This inhibition appears to be mediated via interneurons, activated by axons or axon collaterals of those cells receiving hippocampal inputs.

$$
\text { 10:50-11:05 (171) }
$$

Disruption of Memory by Nonepileptogenic Brain Stimulation. ELAINE BRESNAHAN \& ARYEH ROUTTENBERG, Northwestern University-During avoidance learning ("1-trial passive"), brain stimulation was applied to certain nuclei of the amygdala and hippocampus. Retention $24 \mathrm{~h}$ later showed a deficit in amygdala animals but not in hippocampals. Epileptiform and motivational contributions to disruption were contraindicated.

$$
\text { 11:05-11:25 (172) }
$$

Conditioned and Unconditioned Cardiovascular 
Responses in Rabbits to Subcortical Chemical or Electrical Stimulation. NEIL SCHNEIDERMAN, University of Miami-Short-duration pulse trains of intracranial electrical stimulation or microinjections of norepinephrine served as US for heart-rate (HR) classical conditioning. Systemic injections of autonomic blocking agents confirmed that HR decreases following the US were induced by blood-pressure increases, whereas HR CRs were not dependent upon BP CRs.

$$
11: 30-11: 45 \text { (173) }
$$

Electrical Brain Stimulation as a Pavlovian Conditioned Inhibitor. JOHN W. MOORE, University of Massachusetts-Hypothalamic and lateral or medial geniculate brain stimulation were contrasted as inhibitory CSs in a Pavlovian conditioned inhibition paradigm. Rabbits received differential conditioning of their nictitating membrane response to a tone (CS+) and a compound consisting of the same tone and brain stimulation (CS-). The UCS was eye shock. While stimulation at both sites acquired inhibitory properties, the strongest effects were obtained using bipolar electrodes located in lateral or medial geniculate.

\section{1:45-12:00 (174)}

The Evils of Filtering Bioelectric Signals. W. W. DAWSON, H. W. DODDINGTON, \& C. K. ADAMS, University of Florida-Noise reduction is achieved by active or passive filtering of signals but at the expense of the phase relationships of the signal components. Changes always occur in temporal relationships. These can result in complete inversion of portions of a potential. The effects of filtering are demonstrated. Interference filtering is introduced as a means of noise reduction without phase shift.

\section{ANIMAL SENSORY FUNCTIONS}

\section{$1: 30-1: 40$ (205)}

A Temporal Modulation Transfer Function for the Pigeon. VIRGIL A. GRAF, Dartmouth College-A method for measuring the modulation transfer function for the pigeon is presented. The transfer function for the pigeon is in close agreement with comparable data for human Ss. The possibility of common physiological mechanisms is discussed.

$$
1: 40-1: 55 \text { (206) }
$$

Interactive Effects of Light and Low Temperature on the Goldfish Electroretinogram. G. M. HOPE \& W. W. DAWSON, University of Florida-Goldfish were maintained at low temperature (cold stress) under several ambient lighting conditions, then allowed to recover. The electroretinogram (ERG) was recorded as an index of retinal function. Analysis of ERGs and stimulation conditions were manipulated in order to differentiate effects on photopic and scotopic systems. The effect of low temperature plus light was to reduce the function of both systems. Under light absent conditions, the photopic system was spared, while the scotopic system failed to show the recovery from cold stress normally seen in the presence of light.

$$
\text { 2:00-2:15 (207) }
$$

Effects of Visual and Auditory "Noise" on Delayed Matching in Monkeys. ROBERT WORSHAM \& M. $R$. D'AMATO, Rutgers University (read by $M . R$. D'Amato)-Verifying previous results, performance on a visual delayed matching-to-sample task was superior when darkness, rather than moderate illumination, filled the delay (retention) interval. However, performance was unaffected by the presence of white noise during the retention interval, suggesting that the interference from visual "noise" may be modality specific.

$$
2: 15-2: 25(208)
$$

Discrimination of Metric Patterns in the WGTA by
Rhesus Monkeys. FRED STOLLNITZ, National Science Foundation-Pairs of metric patterns ( 4 by 4 matrices of dark and light cells) are discriminable in the WGTA by rhesus macaques, contradicting a previous claim. Painted patterns (complements) were reduced from 3 to 2 to 1.5 in. square during initial training. Later, performance on new 1.5-in. patterns varied with the number of corresponding cells of different lightness.

$$
2: 30-2: 45(209)
$$

Assimilation and Contrast Effects in Visual Discrimination by Rhesus Monkeys. MARTHA WILSON, University of Connecticut-Sets of visual stimuli were judged by monkeys in a paired-comparison procedure. It was found that discriminability was a function of 2 factors: physical distance between the stimuli and their relationship to the adaptation level of the series. The pertinence of these results to categorical perception and the speech mode was discussed.

\section{MOTIVATION}

$$
\text { 3:05-3:20 (210) }
$$

Sex and Social Attraction in the Albino Rat. LLOYD R. SLOAN \& BIBB LATANÉ, Ohio State University-Rats were observed in either cross- or consex pairs under varying conditions of sexual experience, receptivity, and satiation. These factors strongly influenced sexual behavior but had no effect on social attraction. It appears that sociability in rats is not motivated primarily by sexual desires.

$$
3: 20 \cdot 3: 30(211)
$$

Free-Operant Competitive Behavior in the Laboratory Rat. CHARLES D. CORMAN, West Virginia University, \& ROBERT S. RUSKIN, Georgetown University-The procedures used in determining hierarchies of successfulness in a free-operant competitive situation will be described. The results of several studies related to level of deprivation, schedule of reinforcement, and response generality will be discussed, along with the problem of predicting social behavior on the basis of nonsocial responses.

$$
\text { 3:35-3:50 (212) }
$$

Reversed Alcohol Preference in Rats After Experience with a Sapid Alcohol-Sucrose Solution. JOSEPH W. CULLEN \& ROBERT A. CROES, V.A. Hospital, Perry Point, Md.-Rats, given water and 3\% Etoh solution to drink, show $60 \%$ preference for the latter. If $10 \%$ sucrose is added to the Etoh solution, the preference increases to $80 \%$. However, the sucrose-Etoh experience reduces subsequent $3 \%$ Etoh preference to $40 \%$. This reduction is both stable and reliable for at least 30 days. It is hypothesized that taste experience can clearly reverse alcohol preference.

$$
3: 50-4: 00(213)
$$

Categorizing of Sweet Tastes Using Conditioned Aversion. MAHLON W. WAGNER, SUNY at Oswego-Water-deprived rats were twice given cytoxan injections following saccharin exposure. Subsequent exposure to saccharin, cyclamate, glucose, or water showed that rats seemed to consider cyclamate to taste somewhat similar to saccharin, while glucose and water tasted quite different.

$$
\text { 4:05-4:20 (214) }
$$

Controlling Preferences in Rats. GEORGE WOLFORD \& ED RANSON, Dartmouth College-An attempt was made to determine the variables controlling the preference for barpressing over free food demonstrated in a number of recent studies. It was found that appropriate amounts of barpress or free-food training could lead to a strong preference for barpressing, a strong preference for free food, or the reversal of an established preference.

$$
4: 20-4: 35(215)
$$

Sham Feeding in the Rat. JOHN D. DAVIS, University of Ilinois, Chicago Circle, \& CONSTANCE S. CAMPBELL, University of nlinois Medical Center-The role of the 
stomach in controlling meal size was investigated by removing stomach contents during and after rats drank palatable liquid diets. The results support the view that stomach distention plays a major role in controlling the size of meals of palatable diets in moderately food-deprived rats.

$4: 40-4: 45(216)$

(Read by title only)

The Inhibition of the Acoustic Startle Reaction by Food and Water Deprivation in Rats: A Theoretical Failure for Neo-Hullian Drive Theory. L. FECHTER \& J. R. ISON University of Rochester-Three experiments investigated the effects of food or food and water deprivation (ranging from $3 \mathrm{~h}$ deprivation to $35 \%$ body weight loss) on the normal and inhibited startle reaction, the latter condition produced by presentation of a $20-\mathrm{fc}$ light flash $20-160 \mathrm{msec}$ prior to reflex elicitation. Greatly reduced startle amplitudes were generally observed in deprived Ss under normal conditions and lesser effects were produced on the already inhibited reflex. These findings clearly contradict neo-Hullian drive energization and suggest that earlier demonstrations employing aversive stimuli to elicit conditioned emotional states which facilitated the startle reflex reflected response elicitation rather than drive energization.

\section{BRAIN FUNCTIONS}

$$
8: 45-9: 00(259)
$$

Specificity of Stimuli that Induce Recovery from Experimental Amnesia. RALPH R. MILLER \& ALAN D. SPRINGER, Brooklyn College of CUNY-Immediately after 1-trial training to passively avoid immersion in ice water, rats were rendered amnesic with electroconvulsive shock. Subsequent noncontingent footshock induced recovery of memory. These data indicate that stimuli which induce recovery from experimental amnesia need not be qualitatively similar to the reinforcer used in training.

$$
\text { 9:00-9:10 (260) }
$$

Short-Term Memory (STM) Following Hemisphere Deconnection in Man. SANTOSH KUMAR \& $R$. $W$. S P ERR Y, California Institute of Technology-Graham-Kendall Memory Test designs, adapted for lateralized presentation by touch, were given to 4 patients with complete and 2 with partial commissurotomy. Left-hand (right hemisphere) performance was strongly superior in the former, while right-hand scores showed fewest errors with designs easily verbalized. Lateral superiority was insignificant with partial section.

$$
9: 15-9: 30(261)
$$

Time Series Analysis Effect of Nasal Airflow on Rhinencephalic Electrical Activity. JOHN ORR, University of Michigan, FREDERICK P. GAULT, Western Michigan University, \& WILLIAM STEWART, Emory University-Recordings from rat olfactory bulb and pyriform cortex were subjected to time series analysis to determine the influence of variation in airflow rate on the power spectra. Power increased significantly with increases in flow of deodorized air but maintained the form of the spectrum

$$
\text { 9:30-9:45 (262) }
$$

The Neocortex and Feeding Behavior in the Rat. J. JAY BRAUN, Yale University-Rats lacking neocortex are initially aphagic and adipsic and then severely anorexic. Three months postoperatively, body weight is substantially subnormal and finickiness and prandial drinking are evident. Partial neodecortication, irrespective of locus, lowers body weight set point. The marked similarity between this and the lateral hypothalamic syndrome is noted.

$$
\text { Overlearning and Recovery of Function in the }
$$

Somatosensory System. STANLEY FINGER, GEORGE DANIEL WEESE, \& DOUGLAS NEIMAND, Washington University-Blinded rats with no pretraining, pretraining to criterion, or $100 \%$ overlearning were tested on a ridge-smooth discrimination after removal of somatosensory cortex or control surgery. The lesion group performed worse than its control group in the no-pretraining and criterion conditions, but not after overlearning. Although pretraining improved scores for all groups, only overtraining resulted in normal retention for animals with somatosensory cortical lesions.

$$
\text { 10:00-10:20 (264) }
$$

Some Primitive Contributions of Neocortex to Hearing. RICHARD RAVIZZA, Duke University, \& BRUCE MASTERTON, Florida State University-Normal and decorticate opossums were tested on 10 auditory tasks. The results show that decorticate opossums are not much different from normal opossums along most common psychophysical dimensions, but they are markedly different in azimuth sound-localization acuity and in their rate of habituation to an unexpected sound

\section{BRAIN LESIONS}

\section{0:40-10:55 (265)}

Reversal Learning, Light Aversion, and Thigmotaxis in Septal Rats. JAMES C. MITCHELL \& CHRISTOPHER CHERRY, Kansas State University-Rats with septal lesions and control Ss were trained on position reversals in an apparatus minimizing biases resulting from following the apparatus walls. Septal Ss were markedly superior in reversal learning. When Ss were allowed to follow the walls, septals still showed a minor superiority. The superiority of the septal $S$ may be due to a greater ability to tolerate delays of reinforcement.

$$
10: 55-11: 15(266)
$$

Analysis of DRL Responding by Rats with Septal Damage. PAUL ELLEN \& WILLIAM C. AITKEN, JR., Georgia State University-Septally lesioned and normal rats were trained on a series of DRL schedules having different delay requirements. Normal rats increased their response probabilities as a function of the delay since the previous response on DRL schedules of $10,20,30$, and $40 \mathrm{sec}$, but not on DRL 50 . Septals showed a temporal discrimination only on DRL 10 .

\section{$11: 20-11: 35(267)$}

Effects of Hippocampal Lesions on Sucrose Preference in the Rat. THOMAS S. BROWN, DePaul University, \& HELEN M. MURPHY, John Carroll University-This study compared sucrose-preference behavior of rats with hippocampal lesions, cortical lesions, and normal controls in 5-min and 24-h test sessions. In the 5-min test, hippocampally damaged rats failed to show typical sucrose-preference behavior. However, these same animals were identical to controls in the 24-h test.

$$
11: 35-11: 50(268)
$$

Increased Reactivity to Environmental Stimulation in Rats with Hippocampal Lesions. LEONARD E. JARRARD, Washington \& Lee University-A series of tests were chosen to determine the effects of both external stimuli (intermittent tone and light) and internal stimulation (food deprivation) on activity in the home cage. Rats with hippocampal lesions did not differ from controls at low levels of stimulation but were more active when the stimulation was intense. The results are interpreted as support for the involvement of hippocampus in motivation. 11:55-12:10 (269)

Neonatal Ablation of Somatosensory Cortex: Projections to Remaining Cortex in Adulthood. ROBERT $L$. RAISLER, Michigan State University, EDWIN W. RUBEL, Yale University, \& JOHN I. JOHNSON, JR., Michigan State University-Microelectrode mapping of neocortex in 5 adult cats following bilateral removal of SmI and SmII areas 
neonatally showed auditory and visual projections unchanged and mechanosensory projections only in cases where lesions were incomplete, and these were located as in normal cats. There was no evidence of cortical reorganization.

12:10-12:25 (270)

Extended Training Influences on Object Reversal by Frontal Monkeys. F. ROBERT TREICHLER, Kent State University-Five normal and 5 lateral-frontal macaques received 120 automated successive object reversals to $90 \%$ criteria. Gross performance measures did not differentiate the groups after the first 20 problems, but performance on those trials immediately after reversals differed even on the last 20 problems. This difference appeared attributable to the frontal's failure to adopt consistent win-stay strategies.
$12: 25-12: 30(271)$

(Read by title only)

Influence of Reward Palatability and Level of Body Weight on Work Output of Rats with Ventromedial Hypothalamic Lesions. WILLIAM W. BEATTY \& JAMES E. NELSON, North Dakota State University-Barpressing on FR schedules for $8 \%$ or $32 \%$ sucrose reward was studied in rats with ventromedial hypothalamic (VMH) lesions. When the body weights of the lesioned rats were maintained at control levels by food deprivation, VMH-lesioned animals made reliably more barpresses than did controls for either sucrose concentration on FR schedules from 1 to 16; on higher FRs, the enhanced performance by lesioned rats was evident only when $32 \%$ sucrose was the reward. During the static obese stage, performance by the same VMH-lesioned animals was not reliably different from that of controls at either sucrose concentration, although the lesioned rats worked somewhat harder for $32 \%$ sucrose than for $8 \%$ sucrose. 